\title{
Nanomodification is an effective way of forming a fine-grained structure of a weld metal. Part $I$. Factors determining the stability of the weld seam against embrittlement
}

\author{
A.M. Boldyrev' ${ }^{1}$ iD , S.V. Sizintsev ${ }^{1 *}$ (iD, V.G. Sannikov' ${ }^{1}$ iD, V.F. Pershin ${ }^{2}$ (iD \\ ${ }^{1}$ Voronezh State Technical University, Voronezh, Russia \\ ${ }^{2}$ Tambov State Technical University, Tambov, Russia \\ * Corresponding author: e-mail: sizincev.1991@mail.ru
}

\begin{abstract}
Steel constructions are the most important objects of the construction industry. The main method of connecting individual elements and assemblies of such structures is fusion welding (electric arc, plasma, electron beam). One of the main problems of metal structures is their tendency to brittle fractures that occur suddenly, without noticeable previous deformations, often at below zero temperatures and loads. In this case, $70-80 \%$ of such damage is associated with welding. The nature of the destruction depends not only on temperature, but also on the type of crystal lattice. Metals with a body-centered cubic (bcc) lattice (tungsten, molybdenum, a-iron) are plastic at a relatively high temperature, but become brittle when negative. And metals with a face-centered cubic (fcc) lattice (aluminum, nickel, copper and $\gamma$-iron) are plastic even at temperatures close to absolute zero. With decreasing temperature, the mobility of dislocations and vacancies decreases, the yield strength $\sigma_{s}$ increases, that is, the ductility of the metal decreases. Using the A.F. loffe model showed that the critical temperature of the transition from viscous to brittle fracture with decreasing temperature depends on the rate of increase of $\sigma_{s}$. In austenitic steels ( $\mathrm{fcc}$ lattice with a period a $=0.3645 \mathrm{~nm}$ ), the impurity mobility (paired with a vacancy) through the internode of the lattice is higher, and the growth rate os is lower than that of low-carbon low alloy steels (bcc lattice with a shorter period $\mathrm{a}=0,2861 \mathrm{~nm}$ ). Therefore, the low carbon steels from which structures are made are more sensitive to lower temperatures.

In addition, resistance to brittle fracture depends on the number and size of metal continuity defects (pores, inclusions, low-plastic phases in the structure, etc.), which are stress concentrators. Welds are the main suppliers of such dangerous defects and sources of crack initiation. During crystallization of the weld pool, a coarse, columnar dendritic structure with reduced ductility is formed. The formation of a fine-grained structure of the weld during crystallization helps to increase its ductility. The grain size in the cast metal (in the weld) depends on the crystal growth rate and the rate of their nucleation. When welding, the most effective way to grind the grain in the seam is to increase the rate of nucleation. The introduction of refractory particles of nanoscale order into the weld pool (nanomodification) allows obtaining a fine-grained weld structure.
\end{abstract}

KEYWORDS: brittle fracture of welded structures, crystallization of the weld pool, obtaining a fine-grained structure of the weld.

FOR CITATION: Boldyrev A.M., Sizintsev S.V., Sannikov V.G., Pershin V.F. Nanomodification - an effective way to form a fine-grained structure of the weld metal. Part I. Factors determining the stability of the weld seam against embrittlement // Nanotechnology in construction. - 2020. - Volume 12, № 3. - pp. 160-165. - DOI: 10.15828/2075-8545-2020-12-3-160-165.

\section{INTRODUCTION}

$\mathrm{S}_{\mathrm{itad}}^{\mathrm{ted}}$ teel constructions are the most important objects of the construction industry. The main way to connect the individual elements and nodes of such structures is welding. The transition from riveted to welded constructions ensured an increase in labor productivity, a reduction in labor and material costs. This led to an increase in the range and production of metal structures. Almost $70 \%$ of the global consumption of metal structures is the

(c) Boldyrev A.M., Sizintsev S.V., Sannikov V.G., Pershin V.F., 2020 
production of welded products, structures and facilities. The volume of production of welded structures worldwide is hundreds of millions of tons [1].

One of the main problems of welded metal structures is their tendency to brittle fractures that occur suddenly without noticeable previous deformations, often at low temperatures and loads below design.

According to statistics, $70-80 \%$ of all recorded failures of metal structures are associated with welding $[2,3]$. For the first time, numerous cases of such failures were recorded in the United States, when mass production of welded ships and oil tankers was established [4]. Unfortunately, cases of such destruction both here and abroad continue to take place [5]. More often, such damage occurs at a negative ambient temperature.

In connection with the intensification of development of the northern and eastern territories of Russia, the problem of increasing the resistance of welded metal structures to brittle fractures at low temperatures is of particular relevance [6]. This article discusses the main causes of embrittlement of weld metal, as one of the main sources of nucleation and development of cracks in a welded joint.

\section{METHODS AND MATERIALS}

\section{Mechanics of brittle fracture of metals}

A.F. Ioffe, based on the concepts of two types of fracture: shear (plastic fracture) and chip (brittle), proposed a scheme for the transition of a solid from viscous to brittle fracture (Fig. 1) [7].

According to this scheme, the tensile strength of interatomic bonds in the crystal lattice $\sigma_{\mathrm{b}}$ (brittle strength) is determined by the nature of the substance - the structure of atoms and the type of crystal lattice. Therefore, $\sigma_{\mathrm{b}}$ depends little on temperature. And shear resistance $\sigma_{\mathrm{s}}$ (plastic strength) characterizes the ability of a material to deform without breaking atomic bonds. In polycrystalline bodies, deformation during loading occurs along slip planes - along grain and twin boundaries due to accumulation and dislocation movement in these zones. With decreasing temperature, the number and mobility of dislocations decrease, and the deformation resistance (yield strength $\sigma_{s}$ ) increases. At temperatures lower than $\mathrm{T}_{\mathrm{cr}}$, strains os exceeding the strength of interatomic bonds $\left(\sigma_{s}>\sigma_{b}\right)$ are necessary for deformation of the material; therefore, brittle fracture occurs in this case. Thus, ductility is the main factor determining the resistance of the metal to embrittlement. The nature of the destruction of metals depending on temperature is closely related to the type of crystal lattice. Metals with a body-centered cubic lattice (W, $\mathrm{Mo}, \alpha-\mathrm{Fe})$ and tightly packed hexagonal $(\mathrm{Zn}, \mathrm{Be})$ plastic at a relatively high temperature, become brittle at negative. And metals with a face-centered cubic lattice $(\mathrm{Al}, \mathrm{Ni}, \mathrm{Cu}$, and $\gamma$-Fe in high-alloy austenitic steels) are ductile even at temperatures close to absolute zero. In them, the yield stress increases with decreasing temperature less intensively than in metals with a bcc lattice (curve 2 in Fig. 1). Building metal structures are made mainly of relatively cheap low-carbon low-alloy steels containing more than 90\% $\alpha$-iron with a body-centered cubic lattice. Therefore, with decreasing ambient temperature, the risk of brittle fracture of such structures increases. This danger is caused not only by the high sensitivity of low alloy steels to negative temperatures, but also by the formation of defects in the weld during crystallization of the weld pool in the form of pores, microcracks, and nonmetallic inclusions. Such foreign inclusions are stress concentrators and centers of crack initiation. The magnitude of the increase in stress in the defect zone depends on its size and shape. Near the ellipsoidal inclusion, the stresses $\sigma^{*}$ in comparison with the average $\sigma$ increase by $2 \sigma \sqrt{a / r}[8]$ :

$$
\sigma^{*}=\sigma(1+2 \sqrt{a / r})=\sigma+k,
$$

where $a$ and $r$ - defect length and rounding radius of the sharpest part; $k=2 \sigma \sqrt{a / r}$ - stress intensity factor. That is, the larger the size of the defect and the smaller the radius of its sharpest part, the greater the stress intensity factor, the more dangerous this defect.

If the coefficient $\mathrm{k}$ exceeds a critical value, then the defect becomes the crack nucleus, which, as a result of merging with other microdefects, develops into a main crack.

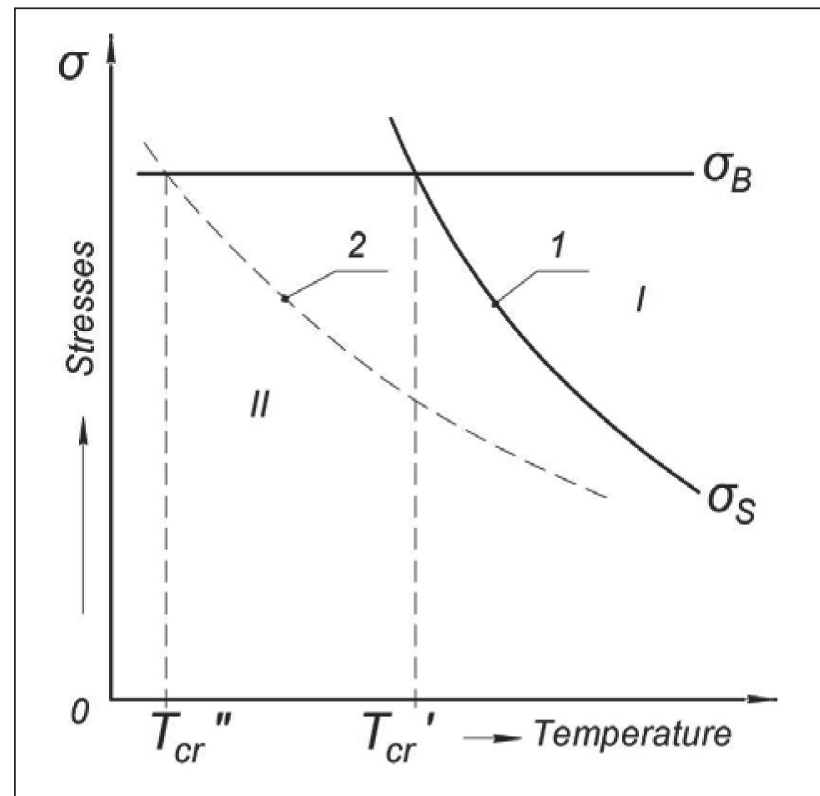

Fig. 1. The scheme of transition of viscous fracture (I) to brittle (II) with decreasing tem-perature [7].

1 - metals with a body-centered cubic lattice;

2 - metals with a face-centered cubic lattice 
It follows that to increase the resistance of weld metal against embrittlement, it is necessary to exclude the appearance or minimize the number and size of such defects. It should also be borne in mind that the sphere is the most favorable form of a defect with a minimum stress concentration. This must be taken into account when additional crystallization centers (modifiers) are introduced into the weld pool. The practice of examining the state of exploited and destroyed welded metal structures showed that welds, whose mass fraction in the structure does not exceed $1 \%$, are the main suppliers of dangerous defects and sources of crack nucleation. Therefore, the reliability and durability of welded metal structures largely depends on the quality of the weld metal. Under alternating or pulsating loads, the fatigue crack nucleates in the weld, in the defect zone or at the point of transition from the weld to the base metal. Its further development completes the destruction of the welded joint or the entire structure.

\section{Specificity of crystallization of the weld pool}

The formation of a welded joint is carried out in a weld pool, which is formed as a result of melting the edges of the connected elements, electrode wire, flux or electrode coating. All these components in the molten state interact with each other and with the gas phase. As the arc moves along the seam in the tail of the weld pool, a crystallization process is carried out, fixing an integral connection of structural elements.

For the first time, the type of structure formed during crystallization of a metal melt under foundry conditions was described by Russian metallurgist D.K. Chernov (1839-1921) [9]. The crystallization conditions of the metal in the weld pool are significantly different from the crystallization conditions of castings. During casting, crystallization of the melt after pouring into the mold proceeds under conditions of continuous cooling, without supply of heat. The latent heat of fusion released during this slows down the growth of crystals, and continuous heat removal leads to supercooling of the melt, which contributes to the endogenous nucleation of new crystals in the central part of the casting. The overheating of the melt in the weld pool is much higher than during casting. In the weld pool, the volume of which is significantly smaller than the casting, the thermal energy of the electric arc is continuously introduced. The temperature of the arc column is more than $6000 \mathrm{~K}$, and in active spots (anode, cathode) the metal heats up to the boiling point. The boundary of the bath is an isothermal surface with a temperature equal to Tm of partially melted grains. This surface is an active initiator of the growth of a new phase. As a result of this temperature difference and the presence of active centers of growth of the solid phase, which prevent the nucleation of new crystals in the melt, the crystals in the bath grow from its boundary to the center (Fig. 2).

Therefore, large columnar dendrites are formed in the weld metal. Such a coarse structure, combined with defects formed during crystallization (pores, non-metallic inclusions, microcracks, etc.), causes a low ductility of the weld metal. At the same time, alloying the weld metal to increase its ductility, as a rule, leads to a decrease in the tensile strength $\sigma_{\mathrm{b}}$. The only way to increase the ductility of a metal without a significant decrease in strength is the formation of a fine-grained structure [10]. In this case, while maintaining intragranular strength, by increasing the number of slip planes and the area of grain boundaries, the possibility of deformation of the metal without its destruction increases.

\section{sizes}

Crystallization kinetics parameters determining grain

Grain in metal science means a crystal grown during the crystallization of a melt from one nucleus.

A mathematical analysis of the process of crystallization of the melt in a limited volume showed that the diameter of the spherical grain $d$ is proportional to the volumetric growth rate of crystalline nuclei $R$ and inversely proportional to the rate of their occurrence in the melt $n$ [11].

$$
d=k \cdot 6 \sqrt{\frac{R}{n}}
$$

where $R\left[\mathrm{~m}^{3} \cdot \mathrm{s}^{-1}\right] ; n\left[\mathrm{~m}^{3} \cdot \mathrm{s}^{-1}\right] ; k$ - coefficient depending on the shape of the growing crystal.

It follows from (2) that for the formation of a finegrained structure, it is necessary to reduce the crystal growth rate and increase the rate of nucleation. When the melt is cooled without heat influx from the outside (as during casting), the crystal growth rate decreases over time and, if there are no refractory impurities, crystallization occurs at a temperature $\mathrm{T}_{\mathrm{p}}$ below the equilibrium $\mathrm{T}_{\mathrm{cr}}: \Delta \mathrm{T}=\mathrm{T}_{\mathrm{cr}}-\mathrm{T}_{\mathrm{p}}(\Delta \mathrm{T}-$ supercooling $)$. Upon reaching supercooling of a certain critical value $\Delta \mathrm{T}_{\text {cr }}$ in the melt in the supercooling zone, spontaneous homogeneous nucleation of new crystals occurs and a fine-grained structure is formed.

During welding, when thermal energy is continuously introduced into the bath, such subcooling cannot be obtained. Therefore, the main direction in solving the problem of obtaining a fine-grained structure of the weld metal under conditions of fusion welding is to find ways to increase the rate of nucleation of crystals in the weld pool $(n)$.

The rate of formation of stable solid phase nuclei in the melt depends on the amount of energy spent on overcoming the potential barrier during the transition of an atom from the liquid phase to the solid, i.e. on the 


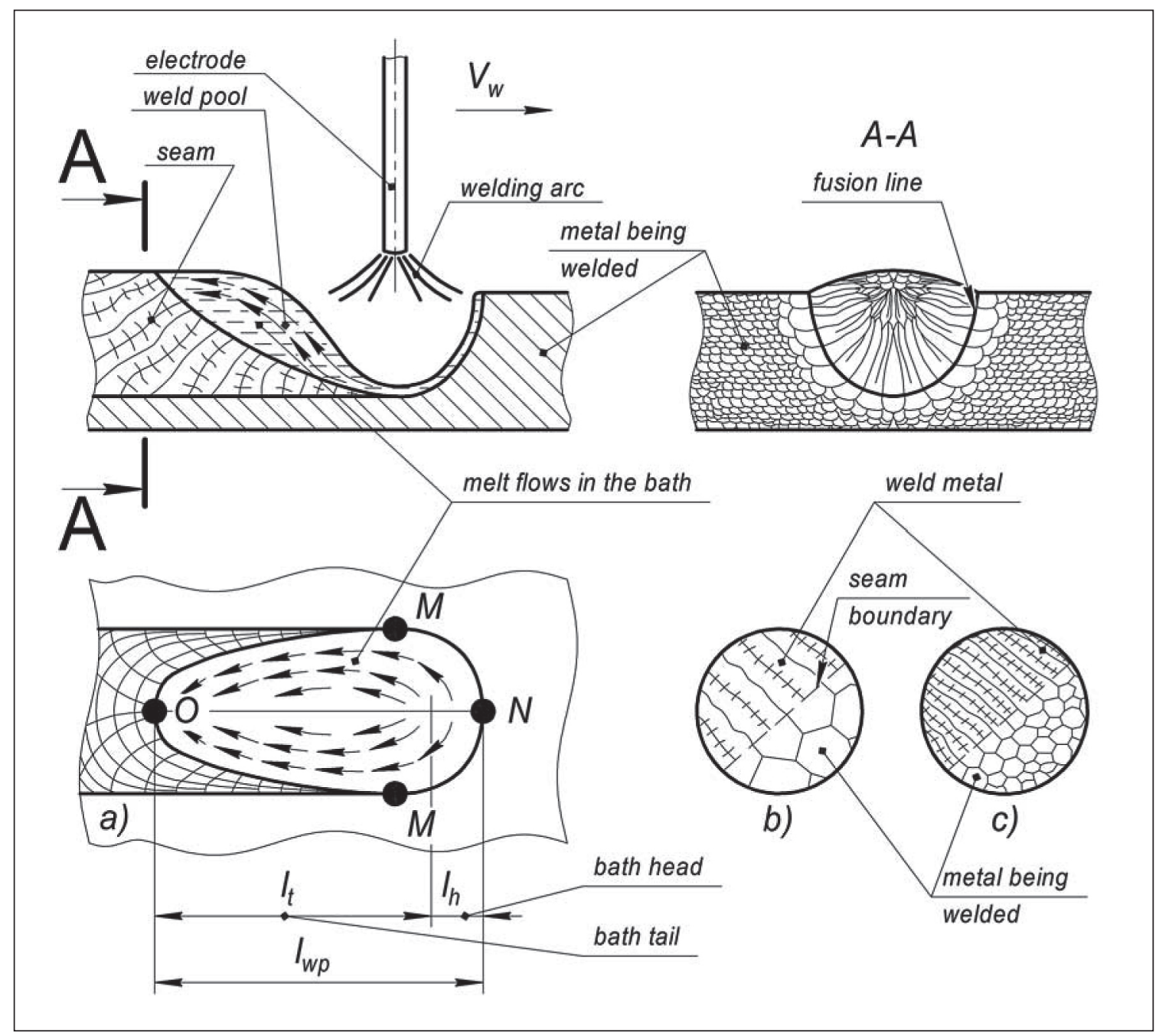

Fig. 2. The scheme of formation of the weld arc welding (a), the formation of the structure of the weld when welding austenitic steel with large (b) and (c) fine grain. $\mathrm{l}_{\mathrm{h}}, \mathrm{l}_{\mathrm{t}}, \mathrm{l}_{\mathrm{wp}}$ - length of the head, tail and total length of the weld pool; $\mathrm{V}_{\mathrm{w}}$ - direction of movement of the welding arc; MNM - and MOM - melting and crystallization front; arrows indicating melt flows in the bath

formation of an interface between the liquid and solid phases. With a decrease in the height of this barrier, the probability of such a transition, and hence the rate of nucleation, increases [12]. The presence of impurities reduces the height of the potential barrier; therefore, the nucleation of crystals in a melt untreated from impurities occurs with very little supercooling, almost at an equilibrium crystallization temperature.

It was established that not all impurities contribute to the nucleation of crystals in the liquid phase, but only those whose type and parameters of the crystal lattice are most consistent with the parameters of the crystallizing substance (P. A. Dankov rule on structural and dimensional correspondence [13]).

The influence of refractory impurities is explained by a decrease in the work of formation of the liquid - crystal interface. The magnitude of this energy gain also depends on the degree of wettability of the impurity particle by the melt. Non-wettable particles do not affect the formation energy, in addition, due to the weak forces of interaction of such particles by the matrix, they are the centers of crack nucleation. When the particles are completely wetted, energy is not required to overcome the potential barrier during the transition of atoms from the liquid phase to the solid. Such particles become active centers of crystallization and are not stress concentrators in the weld metal.

A large number of works have been devoted to ways of influencing the crystallization of the weld pool in order to obtain a fine-grained structure of the weld. These are: activation of refractory particles existing or introduced into the melt, crushing of growing crystals using low-frequency and ultrasonic vibrations, changes in the conditions of 
melt overcooling before the crystallization front due to periodic temperature fluctuations in the crystallization zone, etc. [14, 15].

Currently, it is generally recognized that the most effective way to increase the rate of nucleation of the solid phase in the weld pool is to introduce nanosized particles into the melt of refractory particles (nanomodification), which can be used in combination with other methods of acting on the weld pool.

\section{CONCLUSIONS FOR PART I}

1. Cold brittleness and resistance of the weld metal against brittle fracture is determined by its ductility and type of crystal lattice.
2. Internal defects in the form of accumulations of dislocations, microcracks, foreign inclusions, pores, etc. are stress concentrators.

3. The main supplier of hazardous defects and the source of cracks in the welded joint is the weld metal.

4. The specificity of the crystallization of the weld pool causes the formation of a coarse-grained columnar structure of the weld metal with a lower ductility than that of the base metal. Therefore, the problem of obtaining a weld metal with ultrafine grain, which has high resistance to brittle fracture at low temperatures, is very relevant.

5. Modification of crystallizing metal by introducing refractory particles of nanoscale order into the weld pool is one of the effective ways to grind the weld metal structure, increase its ductility and viscosity.

\section{REFERENCES}

1. Paton B.E. Modern directions of research and development in the field of welding and structural strength. Automatic welding. 2003. No. 10/11. Pp. 7-13. (In Russian).

2. Paton B.E. Modern directions of increasing the strength and resource of welded structures. Automatic welding. 2000. No. 9/10. Pp. 3-9. (In Russian).

3. Hall V., Kihara X., Zut V., Wells A.A. Fragile fracture of welded structures. New York, 1967. (Rus. Edition: Hall V., Kihara X., Zut V., Wells A.A. Fragile fractures of welded structures. Moscow: Publishing House Engineering, 1974. 320 p.).

4. Libovits G. Destruction. Volume 1. Microscopic and macroscopic foundations of fracture mechanics. New York and London, 1968. (Rus. Edition: Libovitz G. Fracture. Volume 1. Microscopic and macroscopic fundamentals of fracture mechanics. Moscow: Publ. Mir, 1973. - 616 p.).

5. Eremin K.I. [and others.] Register of accidents of buildings and structures 2001-2010. Russian Acad. architecture and builds. Sciences [et al.] Moscow: [b.i.], 2011. 318 p. (In Russian).

6. Gorynin I.V., Ilyin A.V. Theoretical and experimental studies of resistance to brittle fracture of welded structures for the shelf of the Arctic. Automatic welding. 2008. No. 11. Pp. 24-29. (In Russian).

7. Ioffe A.F., Kirpicheva M.V., Levitskaya M.A. The deformation and strength of crystals. Journal of the Russian PhysicoChemical Society. The physical part. 1924. Issue 56. Pp. 489-503. (In Russian).

8. Nott, J.F. Fundamentals of fracture mechanics. London, 1978. (Rus. Edition: Nott J.F. Fundamentals of fracture mechanics. Moscow: Publishing House Engineering, 1978. 256 p.).

9. Chernov D.K. The science of metals. Moscow: Publishing. Metallurgizdat, 1950. 556 p. (In Russian).

10. Petch N. Metallographic aspects of destruction. Destruction: in 6 volumes. Volume 1. Microscopic and macroscopic foundations of fracture mechanics. Moscow: Publishing. Mir, 1973. 616 p. (In Russian).

11. Kolmogorov A.N. Toward a static theory of metal crystallization. Bulletin of the USSR Academy of Sciences. The series is mathematical. 1957. No. 3. (In Russian).

12. Umansky Ya.S., Skakov Yu.A. Physics of metals. The atomic structure of metals and alloys. Moscow: Atomizdat, 1974. 352 p. (In Russian).

13. Dankov P.A. The crystal-chemical mechanism of interaction of the crystal surface with foreign elementary particles. Physical Chemistry. 1946. No. 8. Pp. 853-867. (In Russian).

14. Boldyrev A.M., Dorofeev E.B., Antonov E.G. Control of metal crystallization during fusion welding. Welding production. 1971. No. 6. Pp. 35-37. (In Russian).

15. Boldyrev A.M., Grigorash V.V. Problems of micro- and nanomodification of welds during welding of building steel constructions. Nanotechnology in construction. 2011. Volume 3, No. 3. Pp. 42-52. URL: http://nanobuild.ru/ru_RU/journal/ Nanobuild_3_2011_ENG.pdf (accessed: 11.22.2016). (In Russian). 


\section{INFORMATION ABOUT THE AUTHORS}

Alexander M. Boldyrev, Doctor of Engineering, Corr. RAACS, Prof. of Department «Steel and wooden structures», Voronezh State Technical University (VSTU); Voronezh, Russia, ORCID: https://orcid.org/ 0000-0001-9685-4112, e-mail: boldyreff@inbox.ru

Sergey V. Sizintsev, Assistant in Department «Steel and wooden structures», Voronezh State Technical University (VSTU); Voronezh, Russia, ORCID: https://orcid.org/0000-0002-4890-264X, e-mail: sizincev.1991@mail.ru

Vladimir G. Sannikov, PhD in Physics and Mathematics, Associate Professor of Department «Physics», Voronezh State Technical University (VSTU); Voronezh, Russia, ORCID: https://orcid.org/0000-0001-6153-5920, e-mail: sannikov@mail.ru Vladimir F. Pershin, Doctor of Engineering, Professor of Department of «Technique and production technology of nanoproducts», Tambov State Technical University (TSTU); Tambov, Russia,

ORCID: https://orcid.org/0000-0002-0213-9001, e-mail: pershin.home@mail.ru

\section{Author declare the absence of any competing interests.}

Received: 30.04 .2020$.

Revised: 26.05.2020.

Accepted: 02.06.2020. 